\title{
Dip-coating of 8YSZ nanocrystalline particles on NiO-YSZ substrate
}

\author{
SHAHAB MOGHADAS*, AMIR MAGHSOUDIPOUR, TOURADJ EBADZADEH \\ and MASOUD ALIZADEH \\ Ceramic Division, Materials and Energy Research Centre, P.O. Box 31787-316, Karaj, Iran \\ *Author for correspondence (s17.moghadas@gmail.com)
}

MS received 31 October 2011; accepted 29 May 2012; published online 23 March 2019

\begin{abstract}
In this study, $8 \mathrm{~mol} \%$ yttria-stabilized zirconia (8YSZ)-agglomerated particles were dispersed in de-ionized water using different weights of Tiron. The results of viscosity and sedimentation measurements of each suspension were evaluated and the optimum amount of Tiron was selected. The most stable suspension was prepared for dip-coating. The substrate was prepared by mixing $\mathrm{NiO}$ and YSZ powders and then pressed and pre-sintered at $1050^{\circ} \mathrm{C}$. The effect of saturated and unsaturated substrates on morphology and thickness of films were investigated. The thickness of YSZ films with different withdrawn speeds and dip-times were calculated. Also, the morphologies of deposited films were characterized by scanning electron microscopy. The above experimental results showed that by adjusting $\mathrm{pH}$ about 10, the view point of rheological behaviour, the optimum dispersant was $0.8 \%$ and the suspension containing $0.8 \%$ Tiron had the lowest viscosity. Finally, the obtained layers from dip-coating method represented that the films deposited on saturated substrate were crack-free and homogeneous when compared to unsaturated substrates.
\end{abstract}

Keywords. Dip-coating; saturated substrate; NiO-YSZ; Tiron; viscosity.

\section{Introduction}

Zirconia is one of the ceramic material with several applications related to electrical, mechanical and thermal properties. As pure zirconia is not useful for these applications, suitable properties were obtained by adding different percentages of yttria to zirconia [1].

Many dispersants such as aluminon [2], polymethacrylic acid (Darven C), diammonium citrate (DAC) and polyethyleneimine (PEI) [3], Triton-X114 [4], phosphate ester (PE) [1], $\mathrm{NH}_{4} \mathrm{PAA}$ and $\mathrm{NH}_{4}$ PMAA [1], Dolapix CE 64 [1], sodium polystyrene sulphonate (PSS) [5], ammonium polymethacrylate (APMA) [6], etc. in aqueous media and some different dispersants such as polyester-phosphate (PE-312) [4] and menhaden fish oil (MFO) [7] in organic media have been used to prepare stabilized zirconia suspension. In this study, Tiron [4-5-dihydroxy-1,3-benzenedisulphonic acid disodium salt $\left.\left(\mathrm{C}_{6} \mathrm{H}_{4} \mathrm{Na}_{2} \mathrm{O}_{8} \mathrm{~S}_{2}\right)\right]$ is selected as a dispersant agent that causes electrostatic repulsion leading to stabilized suspension.

Various attempts have been made to prepare films using plasma spray, tape casting, spray pyrolysis, RF sputtering, sol-gel, chemical vapour deposition (CVD), electron-beam physical vapour deposition (EB-PVD), screen printing, electrochemical vapour deposition (EVD), etc. [8-10]. One appropriate method for the preparation of well-dispersed $8 \mathrm{~mol} \%$ yttria-stabilized zirconia (8YSZ) suspension is colloidal processing [9]. Dip-coating is one of the colloid processing and when compared to other deposition methods, it is an easy, inexpensive, industrial and economical method for preparing thin films on porous and dense substrate [3,9]. Dip-coating slurries are similar to the composition of suspensions used in tape-casting method [11,12].

YSZ thin films deposited by dip-coating method on NiOYSZ substrate had several applications in electrolytes of solid oxide fuel cell (SOFC) membrane. Ni-YSZ cermet is the most popular anode material for $\mathrm{SOFC}$, but in most cases, the $\mathrm{Ni}$ YSZ, SOFC anode is first made with $\mathrm{NiO}$ and then with YSZ. $\mathrm{NiO}$ is reduced to nickel metal when exposed to the fuel in fuel cell [13-15].

In this paper, suspensions containing 8YSZ with de-ionized water and Tiron as a dispersant were prepared. Furthermore, 8YSZ thin films were deposited on NiO-YSZ saturated and unsaturated substrates as this is the major objective and aim of this work. Subsequently, the effect of saturated and unsaturated substrates on the prepared thin film was evaluated.

\section{Materials and methods}

Granules of yttria-stabilized zirconia ( $8 \mathrm{~mol} \%$ yttria cubic zirconia (TZ-8Y)) purchased from TOSOH Company (Japan) were used as starting materials for the preparation of suspensions. The surface area of this powder was $16 \pm 3 \mathrm{~m}^{2} \mathrm{~g}^{-1}$. Tiron was used as a dispersant agent for stabilizing $8 \mathrm{YSZ}$ (available from FLUKA Chemical, UK). NiO black powder 
Table 1. Suspension formulations.

\begin{tabular}{cccr}
\hline $\begin{array}{c}\text { Solid } \\
\text { content }(\mathrm{g})\end{array}$ & Water $(\mathrm{cc})$ & Dispersant $(\mathrm{g})$ & $\mathrm{pH}$ \\
\hline 9 & 30 & 0 & 10 \\
9 & 30 & $0.2 \%(9 \mathrm{~g})=0.018(\mathrm{~g})$ & 10 \\
9 & 30 & $0.4 \%(9 \mathrm{~g})=0.036(\mathrm{~g})$ & 10 \\
9 & 30 & $0.6 \%(9 \mathrm{~g})=0.054(\mathrm{~g})$ & 10 \\
9 & 30 & $0.8 \%(9 \mathrm{~g})=0.072(\mathrm{~g})$ & 10 \\
9 & 30 & $1 \%(9 \mathrm{~g})=0.09(\mathrm{~g})$ & 10 \\
9 & 30 & $0.8 \%(9 \mathrm{~g})=0.072(\mathrm{~g})$ & 8 \\
9 & 30 & $0.8 \%(9 \mathrm{~g})=0.072(\mathrm{~g})$ & 9 \\
9 & 30 & $0.8 \%(9 \mathrm{~g})=0.072(\mathrm{~g})$ & 10 \\
9 & 30 & $0.8 \%(9 \mathrm{~g})=0.072(\mathrm{~g})$ & 11 \\
\hline
\end{tabular}

with high purity, manufactured by MERCK Company, was used for the preparation of substrate.

\subsection{Preparation of suspensions}

Different slurries were prepared as given in table 1. The flow chart of the preparation process of suspensions is shown in figure 1. $\mathrm{pH}$ of the different suspensions was adjusted using $\mathrm{KOH}$ (1 M).

\subsection{Rheological experiments}

The prepared zirconia suspensions were aged overnight. The rheological properties of the zirconia suspensions were measured by Physica MCR 300 rheometer (produced by Auton Pear). All rheological measurements were carried out at $25^{\circ} \mathrm{C}$

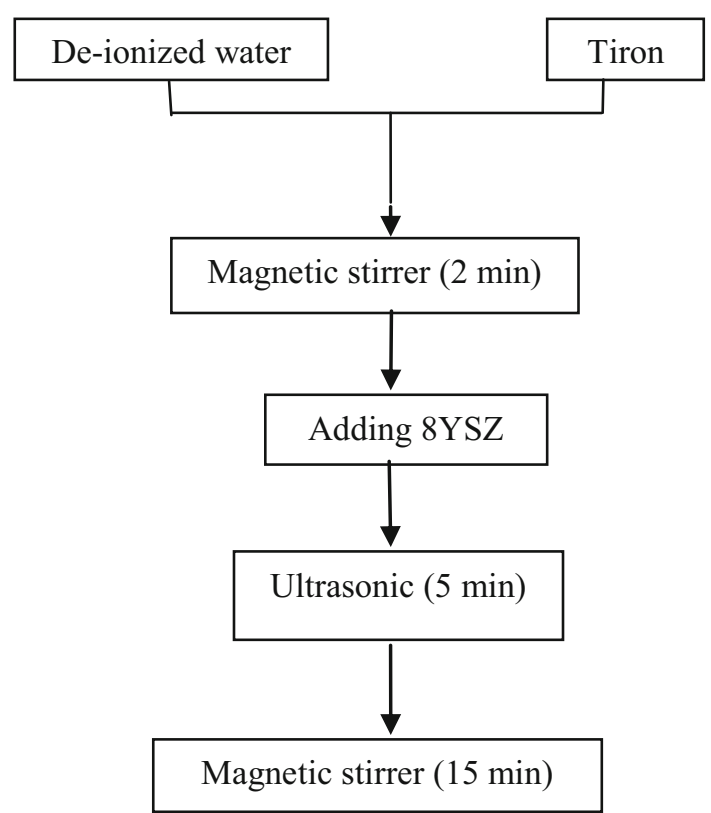

Figure 1. Flow chart of the preparation process for suspensions.

and with constant volume of suspension $(27 \mathrm{cc})$. The effect of different weights of Tiron on shear rate and shear stress was conducted in the range of $0.1-100 \mathrm{~s}^{-1}$.

\subsection{Sedimentation measurements}

Some tubes with same height and radius were selected for sedimentation measurements. Suspensions with various weights of powder and dispersant were aged for $24 \mathrm{~h}$ and then poured

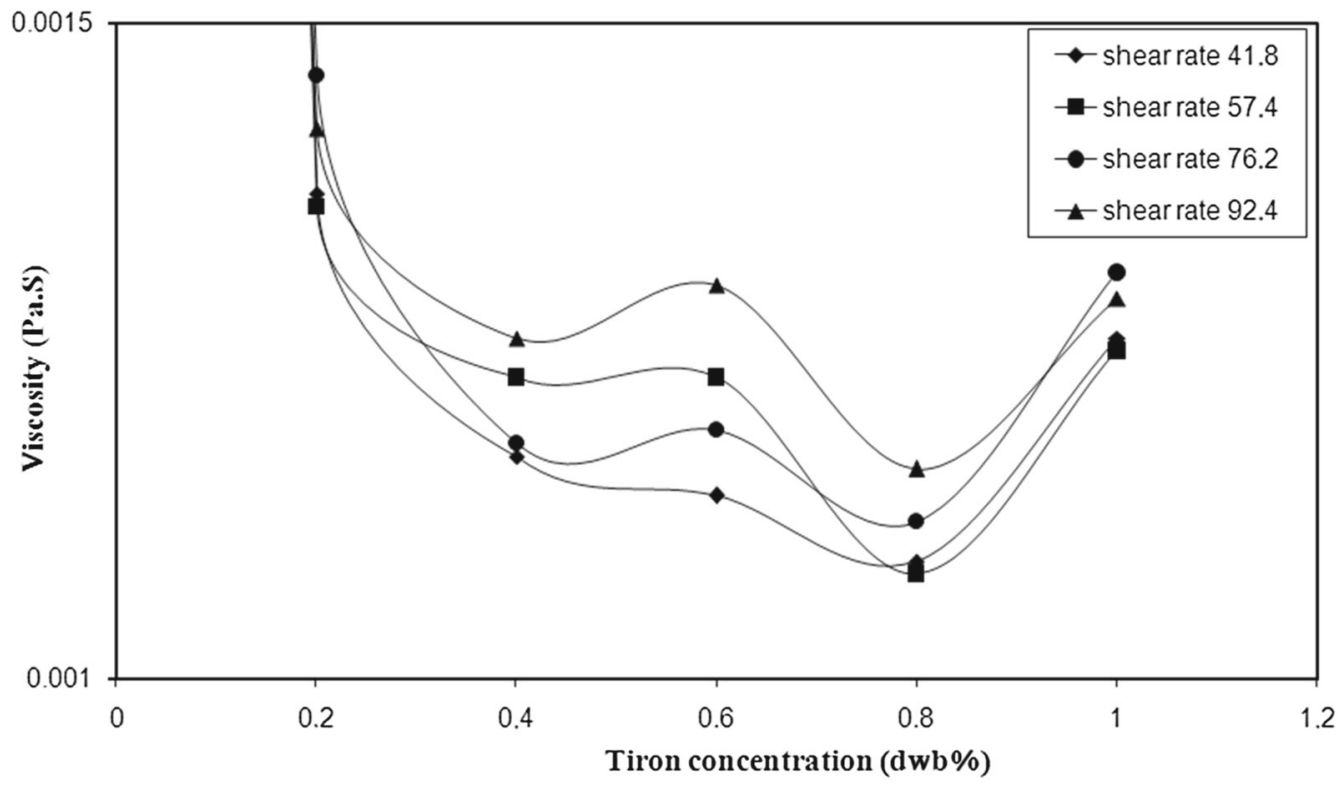

Figure 2. Dependence of viscosity on concentration of Tiron for various shear rates at $\mathrm{pH}=10$. 


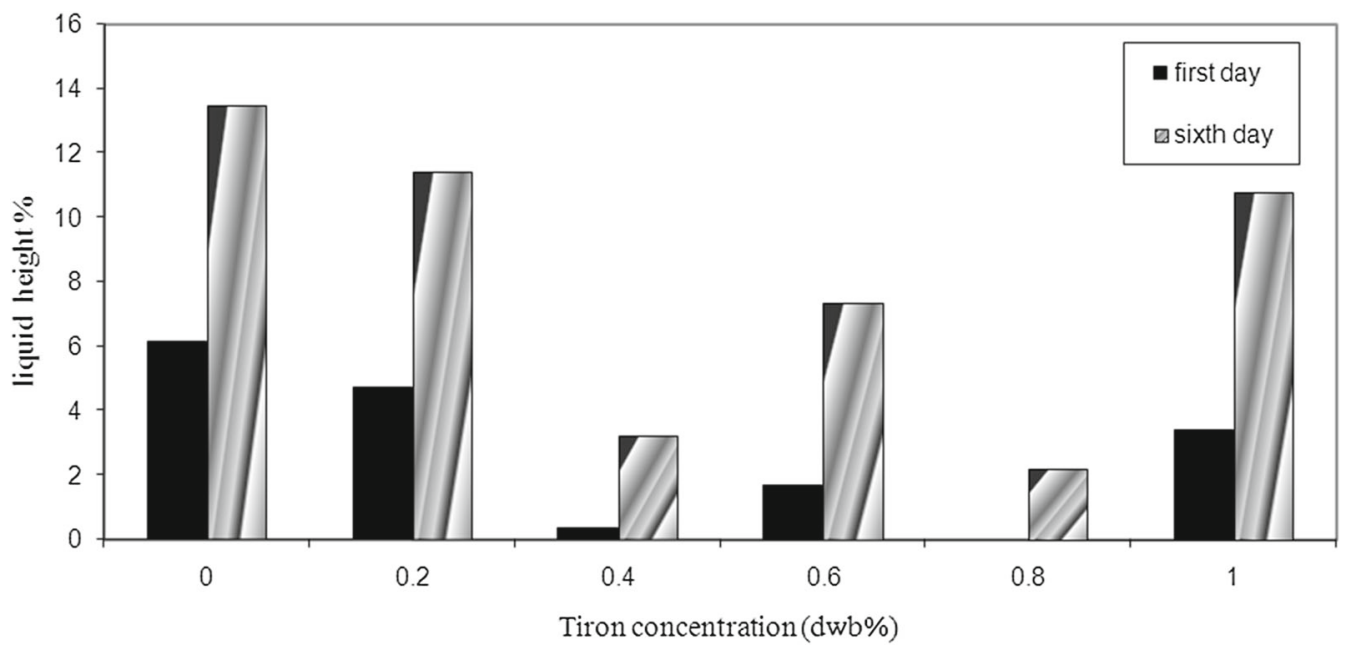

Figure 3. Sediment height as a function of Tiron concentration (dwb \%).

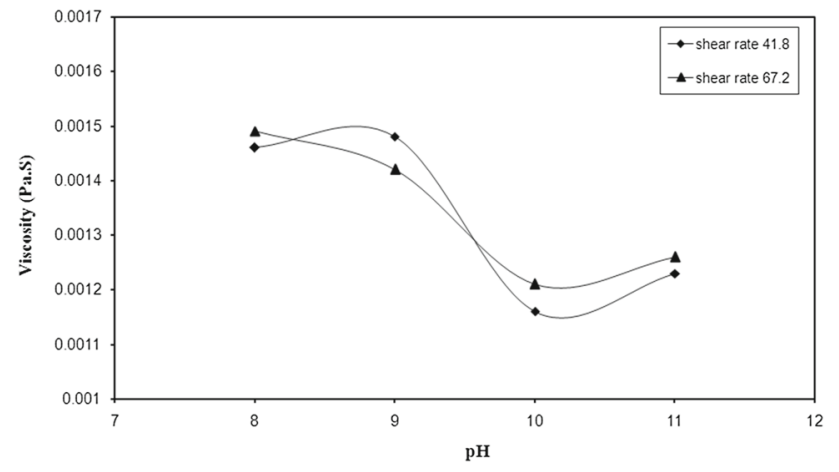

Figure 4. Variation of viscosity at different $\mathrm{pHs}(0.8 \mathrm{wt} \%$ Tiron).

into tubes at same height. After one and six days, the height of clear liquid was measured.

\subsection{Preparation of $\mathrm{NiO}-\mathrm{YSZ}$ substrates}

$\mathrm{NiO}$ and YSZ (1:1 wt\%) powders were mixed with vibrating mixer (CRESTON GLEN, US) for $10 \mathrm{~min}$. Then, the mixed powders pressed into pellets (diameter $10 \mathrm{~mm}$, pressure $300 \mathrm{MPa})$ and subsequently pre-sintered at $1050^{\circ} \mathrm{C}$ with $5^{\circ} \mathrm{C} \min ^{-1}$ for $2 \mathrm{~h}$. The porosity of substrates was calculated by Archimedes' principle. Eventually, the surface of substrates was polished using SiC 800, 1000 and 1200 papers.

\subsection{Deposition on NiO-YSZ substrates}

The most stable solutions with regard to rheological and sedimentation tests, deposited on NiO-YSZ substrates by dip-coating method are with several states: saturated and unsaturated substrates, dip-times of 5 and withdrawn speed of $10 \mathrm{~cm} \mathrm{~min}^{-1}$. Thickness of all the films were calculated by DEKTAK 8000 instrument and their morphologies were investigated using scanning electron microscopy (SEM) stereo scan 360 (Cambridge). Furthermore, the phase composition of YSZ coating and NiO-YSZ substrate were identified by X-ray diffraction (XRD, Unisantis/XMD300) with $\mathrm{Cu} \mathrm{K} \alpha$ radiation at room temperature.

\section{Results and discussion}

\subsection{Rheological and sedimentation behaviours}

In figure 2 , the viscosity is plotted $v s$. the amount of Tiron (wt\%) in different shear rates. As seen in figure 2, the lowest viscosity was obtained for the suspension containing $0.8 \mathrm{wt} \%$ Tiron at $\mathrm{pH}=10$. According to the DLVO theory, the concentration $>0.8 \mathrm{wt} \%$ (the remained dispersant) which is not absorbed on the particle's surface, entered into the media thus, it increases the ionic strength and therefore, flocculation occurs [16]. It is important to point out another reason for increase in viscosity is the interaction between dispersants [1]. When the concentration of Tiron is $<0.8 \mathrm{wt} \%$ then the $8 \mathrm{YSZ}$ surface are not completely covered by dispersant that leads to attraction of $8 Y S Z$ particles. Therefore, the agglomeration occurs and viscosity increases [17].

The results of sedimentation tests for different weights of Tiron are shown in figure 3. As shown, $0.8 \mathrm{wt} \%$ suspension has the lowest height of the clear liquid and as a result, the mentioned suspension is well-dispersed and it is certainly adapted to the other obtained result (figure 2). Up to $0.8 \mathrm{wt} \%$ Tiron, with increase in the Tiron concentration, more surface area is covered, thereby resulting in the general increase in the surface charge and more stability is provided [8]. As mentioned above, according to the DLVO theory, $>0.8 \mathrm{wt} \%$ Tiron, due to decrease in the thickness of double layer, the particles in suspension were agglomerated and settled down rapidly. 


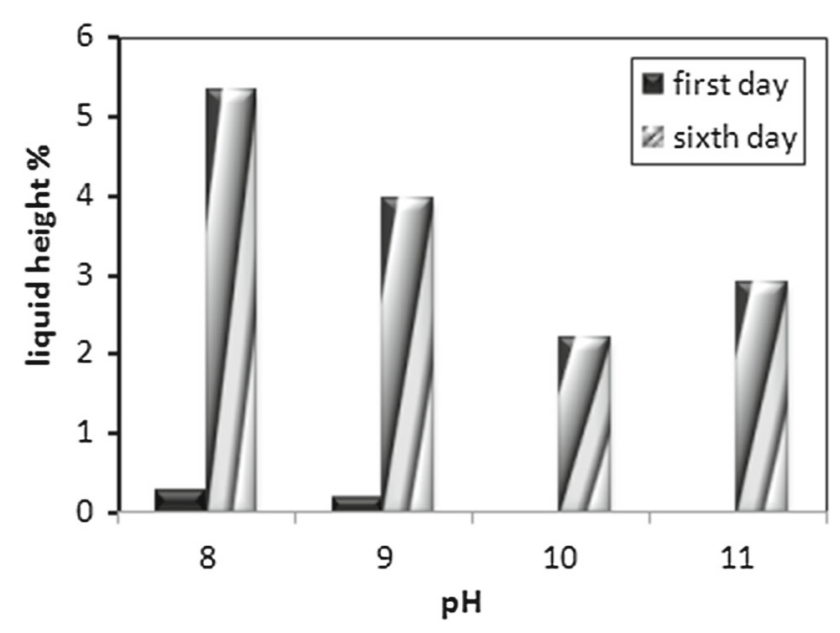

Figure 5. Sedimentation tests as a function of $\mathrm{pH}(0.8 \mathrm{wt} \%$ Tiron).

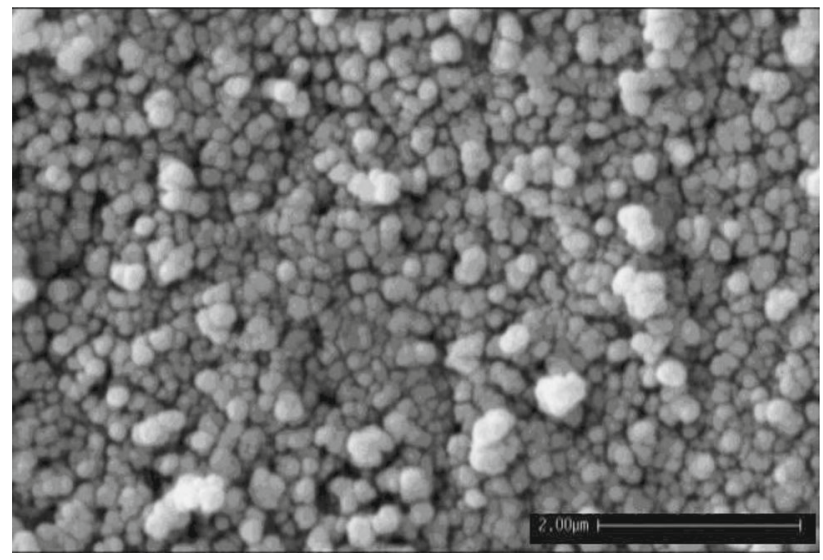

Figure 6. SEM image of NiO-YSZ substrate.

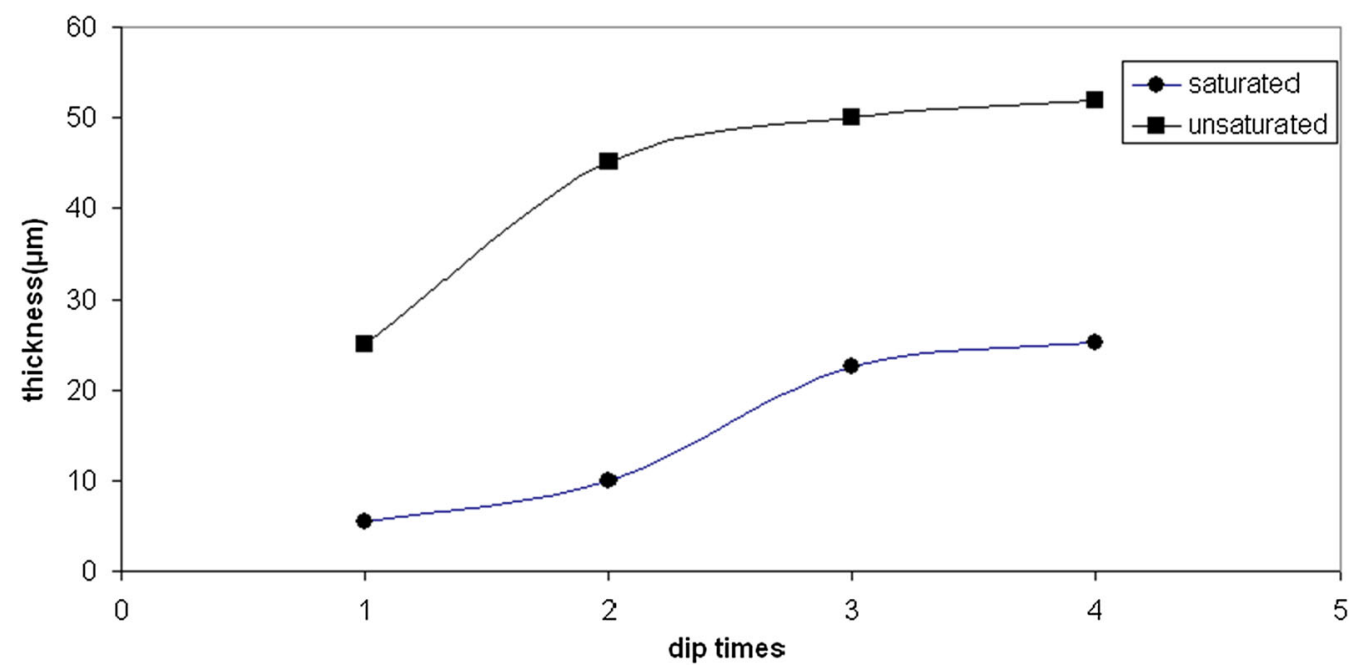

Figure 7. Film thickness as a function of dip times.
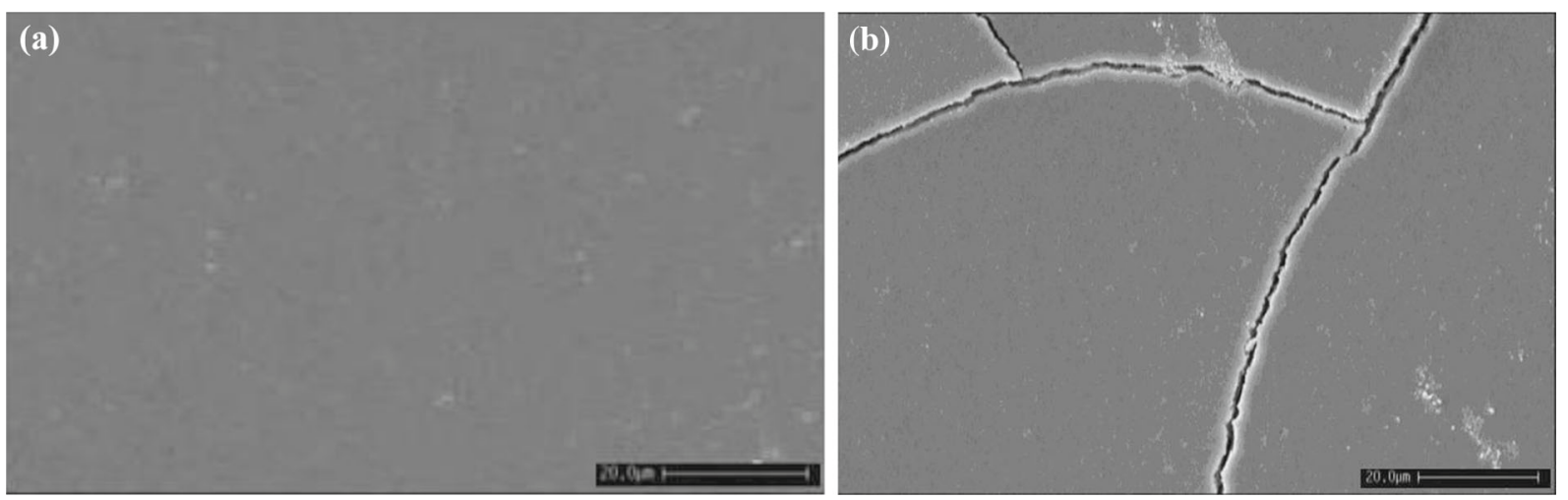

Figure 8. SEM images of the surface morphology (one-time dipping) of (a) saturated and (b) unsaturated substrates.

Figure 4 illustrates the viscosity of 0.8 wt $\%$ Tiron (optimum of the dispersant) against $\mathrm{pH}$ (suspension no. 7-10). As shown, the lowest viscosity is related to the suspension that prepared at $\mathrm{pH} 10$. It is worth mentioning that while $\mathrm{pH}$ $>10$, the additional $\mathrm{KOH}$ for adjusting $\mathrm{pH}$ acts as an electrolyte and therefore, this phenomenon causes an increase 
in ionic strength and, agglomeration occurs [3]. At $\mathrm{pH}<10$, amount of $\mathrm{OH}^{-}$is not sufficient for covering the $8 \mathrm{YSZ}$ particle's surface and as a result, the viscosity of the suspension increases.

Figure 5 represents liquid heights at different $\mathrm{pHs}$ on suspensions containing $0.8 \mathrm{wt} \%$ Tiron. These results are completely in agreement with the consequences obtained from figure 4.

In summary, according to the aforesaid reasons, it is concluded that the stabilized and well-dispersed suspension was obtained with 0.8 wt\% Tiron at $\mathrm{pH} 10$.

\subsection{Specifications of NiO-YSZ substrate}

Ten substrates were selected; and density and porosity percentages were calculated according to Archimedes' principle. The results show that the values of density, shrinkage and porosity percentages are about $3.9 \mathrm{~g} \mathrm{~cm}^{-3}, 6.75 \%$ and $36 \%$, respectively.

Figure 6 shows the surface of pre-sintered NiO-YSZ substrate. As it can be observed in this figure that due to pre-sintering the necking phenomenon occurs and the porosities are observed.
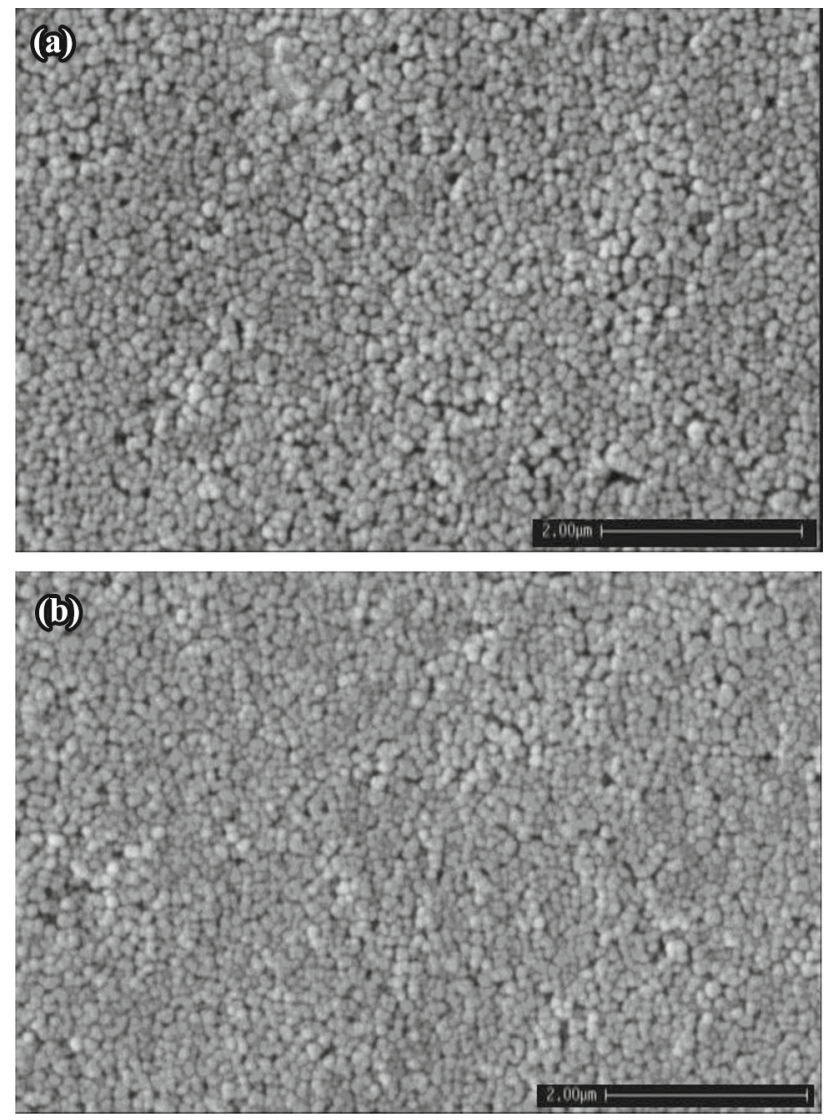

Figure 9. SEM micrographs of the surface morphology (one-time dipping) of (a) saturated and (b) unsaturated substrates.

\subsection{Comparison between saturated-and unsaturated-coated substrates}

For the preparation of saturated substrates, a substrate must be placed inside de-ionized water for $30 \mathrm{~s}$ to fill the porosities of the substrate. In figure 7, the relationship between dip-times

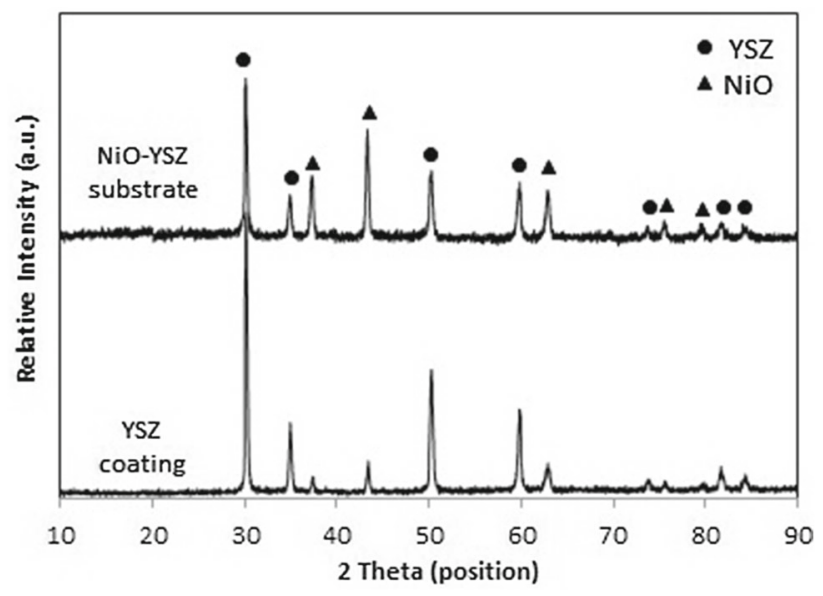

Figure 10. XRD patterns of YSZ coating and NiO-YSZ substrate.
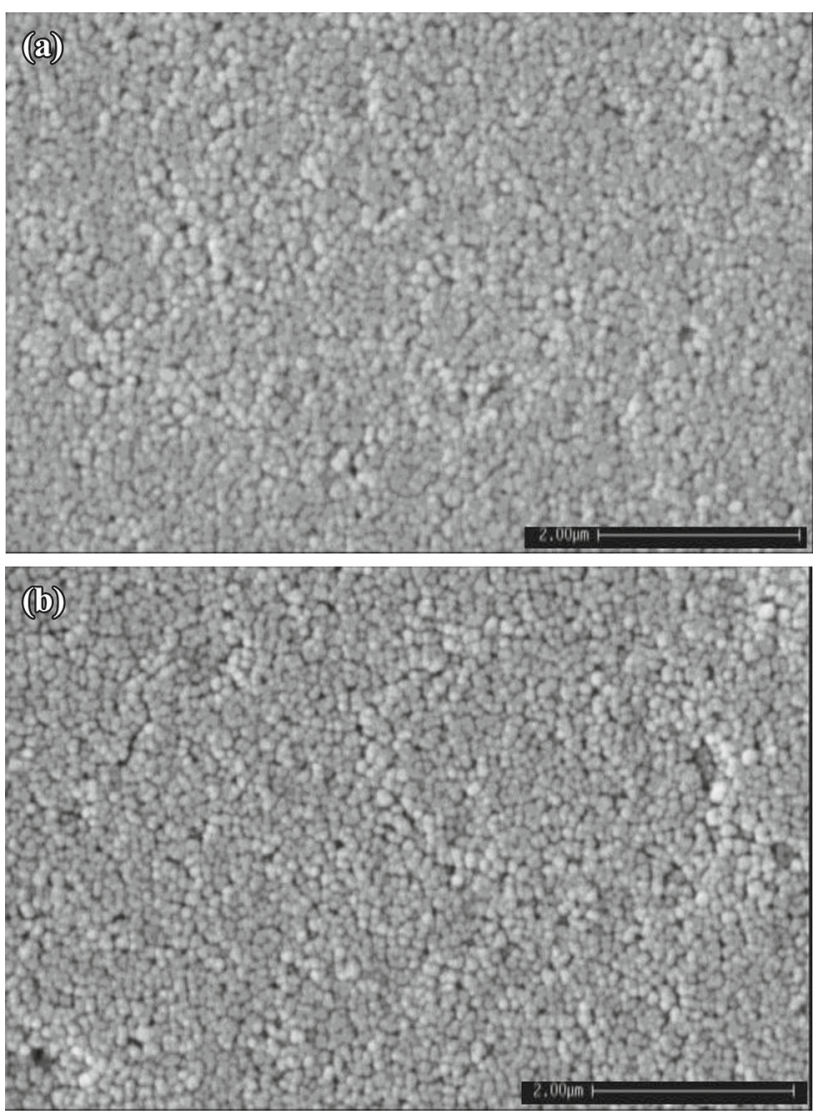

Figure 11. SEM images of the surface morphology (four-times dipping) (a) saturated and (b) unsaturated substrates. 
and film thickness in both saturated and unsaturated substrates with $10 \mathrm{~cm} \mathrm{~min}^{-1}$ withdrawal speed has been investigated. As it can be seen, the saturated substrates filled their porosity with de-ionized water and hence, reducing capillary suction and pressure. Thus, the coated film thickness of the saturated substrates is less than the unsaturated ones [18].

Figure 8 shows the SEM micrograph of the 8YSZ film obtained from one-time dip-coating on saturated and unsaturated NiO-YSZ. The deposited film on unsaturated substrate after one-time dip-coating has cracks because of capillary suction of available porosities (figure 8b), but the mentioned cracks are not observed on the surface of the film that coated on saturated substrate (figure 8a).

Comparison between morphology of the films in both saturated and unsaturated substrates are shown in figure 9 . In both the substrates, the coated films represent that the suspension is well-dispersed and particle size is about $60-80 \mathrm{~nm}$. It is

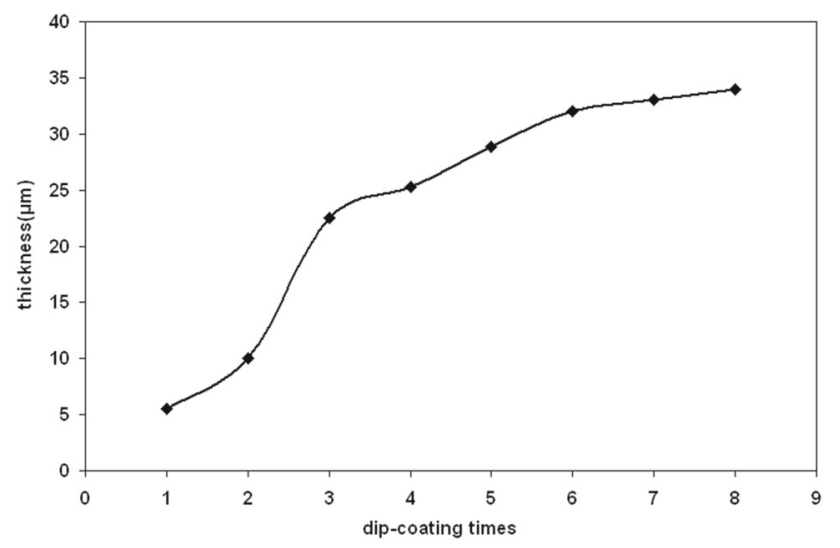

Figure 12. Effect of dip-coating times on thickness (saturated substrate). important to point out that the coating morphology does not depend on the kind of the substrates (saturated and unsaturated substrates). In fact, the coating morphology of the mentioned substrates is related to well-dispersion of the suspension that prepared by optimum percentage of dispersant.

The XRD patterns of NiO-YSZ substrate and YSZ coating are shown in figure 10. As shown, all diffraction peaks of YSZ coating are confirmed to correspond to the cubic structure of YSZ (JCPDS no. 82-1246).

Difference in morphology of coatings with varying dipping times is not distinguished, but this factor only affects the amount of porosity and cracks of the coatings (figure 11). With increase in dipping times, the surface defects such as cracks are decreased [9].

As illustrated in figure 12, the rate of increase in film thickness is reduced with increase in dipping times.

\subsection{Comparison between withdrawn speeds}

According to previous results, a saturated substrate was chosen and differences between two various withdrawal speeds ( 5 and $10 \mathrm{~cm} \mathrm{~min}^{-1}$ ) on the film thickness were investigated (figure 13). With the increase in withdrawn speed, the thickness increases. Direct relationship between withdrawn speed and thickness confirmed by Deryagin's formula [19] given below:

$$
h=[\eta U / \rho g \sin (\alpha)]^{\frac{1}{2}},
$$

where $h$ is film thickness, $\eta$ the viscosity, $\rho$ the density of solvent, $U$ the withdrawal speed $\left(\mathrm{cm} \mathrm{min}^{-1}\right), g$ the gravity acceleration and $\alpha$ the acute angle between horizontal solution surface and substrate. According to Deryagin's formula, with increase in the substrate speed withdrawal, the film thickness

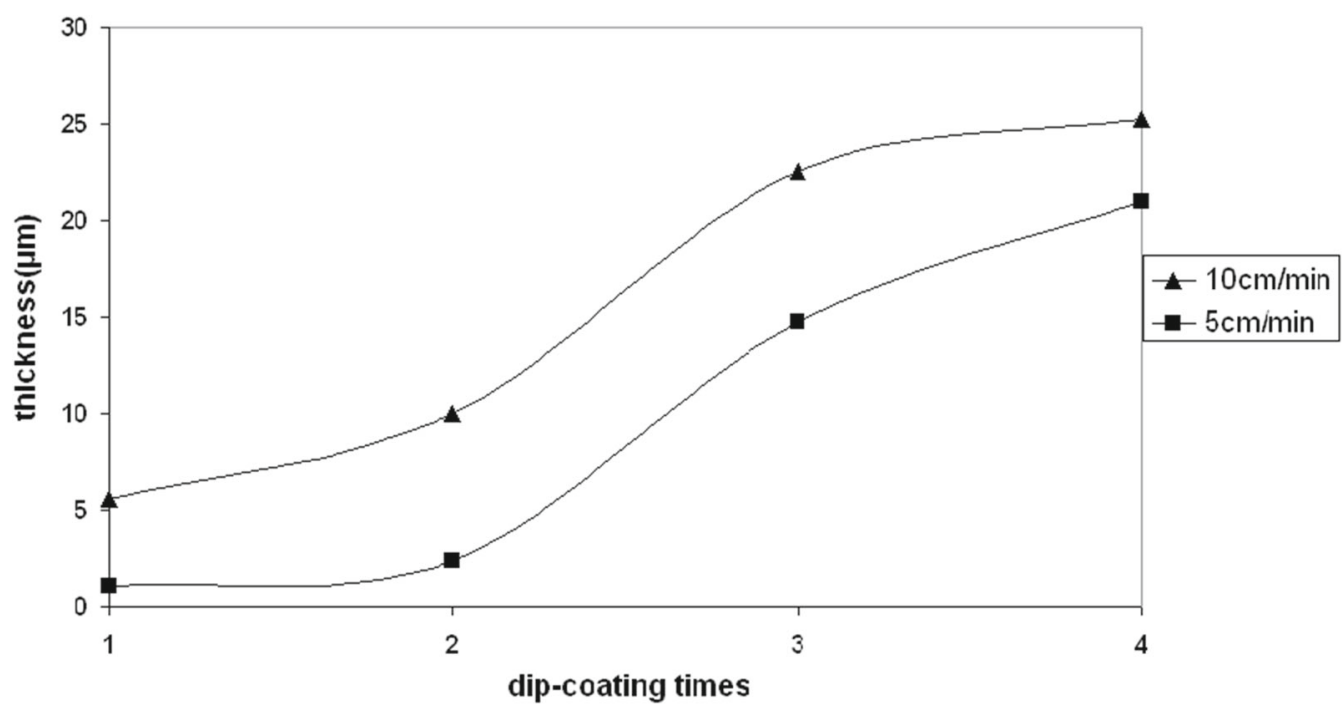

Figure 13. Variations of thickness with dip-coating times in two withdrawn speeds. 
increases. Conversely, with reduction in withdrawn speed, the film thickness decreases.

\section{Conclusions}

In our study the following conclusions can be drawn:

1. $0.8 \mathrm{wt} \%$ Tiron as a dispersant at $\mathrm{pH} 10$ due to an electrostatic repulsion, which was found to be the most stable 8YSZ suspensions in de-ionized water.

2. This study ascertained that the films deposited on saturated substrates when compared to unsaturated substrates were crack-free, homogeneous and continuous. Furthermore, the thickness of coating in saturated substrate was lower than unsaturated one.

3. The film thickness of one dipping time on saturated substrate was about $5 \mu \mathrm{m}$, and with increasing dipping time (up to 8), the rate of increasing thickness was reduced and was about $32 \mu \mathrm{m}$.

4. Eventually, an increase in withdrawn speed causes an increase in the film thickness.

\section{References}

[1] Mukherjee A, Maiti B, Sharma A D, Basu R N and Maiti H S 2001 Ceram. Int. 27731

[2] Briscoe B J, Khan A U and Luckham P F 1998 J. Eur. Ceram. Soc. $\mathbf{1 8} 2169$
[3] Fengqiu T, Xiaoxian H, Yufeng Z and Jingkun G 2000 Ceram. Int. 2693

[4] Zhang J, Ye F, Sun J, Jiang D and Iwasa M 2005 Colloids Surf. A Physicochem. Eng. Asp. 254199

[5] Jachimska B and Adamczyk Z 2007 J. Eur. Ceram. Soc. 27 2209

[6] Saravanan L and Subramanian S 2005 Colloids Surf. A 252175

[7] Kim S D, Hyun S H, Moon J, Kim J-H and Song R H 2005 J. Power Sources 13967

[8] Gaudon M, Liberty-Robert Ch, Ansart F and Stevens P 2006 J. Eur. Ceram. Soc. 263153

[9] Zhang Y, Gao J, Peng D, Guangyao M and Liu X 2004 Ceram. Int. 301049

[10] Pan Y, Zhu J H, Hu M Z and Payzant E A 2005 Surf. Coat. Technol. 2001242

[11] Mauvy F, Lenormand P, Lalanne C, Ansart F, Bassat J M and Grenier J C 2007 J. Power Sources 171783

[12] Lenormand P, Caravaca D, Laberty-Robert C and Ansart F 2005 J. Eur. Ceram. Soc. 252643

[13] Minh N Q and Takahashi T 1995 Science and technology of ceramic fuel cells (Amsterdam: Elsevier)

[14] Pratihar S K, Sharma A D, Basu R N and Maiti H S 2004 J. Power Sources 129138

[15] Fukui T, Ohara S, Naito M and Nogi K 2003 Powder Technol. 13252

[16] Nikumbh A K, Schmidt H, Martin K and Porz F 1991 J. Mater. Sci. 263649

[17] Prakash S, Tripathy S and Raichur M 2007 Colloids Surf. A 302 553

[18] Jeffrey Brinker C and Hurd A J 1994 Phys. Abstracts 41231

[19] Wachtman J B and Haber R A 1993 Ceramic films and coatings (New Jersey, USA: Noyes Publications) 